\title{
Lightweight steel concrete structures slab panels load-bearing capacity
}

\author{
Vladimir Rybakov ${ }^{1 *}$, Anatoly Seliverstov ${ }^{2}$, Denis Petrov $^{2}$, Andrei Smirnov ${ }^{1}$, and Anna \\ Volkova $^{1}$ \\ ${ }^{1}$ Peter the Great St. Petersburg Polytechnic University, Politekhnicheskaya, 29, Saint-Petersburg, \\ 195251, Russia \\ ${ }^{2}$ Intech LB, Ltd, Ispolkomskaya, 4-6, letter A, room 4H, Saint-Petersburg, 196024, Russia
}

\begin{abstract}
Lightweight steel concrete structures (LSCS) - an innovative building structure type that can be used both as load-bearing and as enclosing one. They consist of profiled steel - usually galvanized and coldbent - filled with a monolithic foam concrete with a $200 \mathrm{~kg} / \mathrm{m} 3$ density, and with fiber cement sheets sheathing. These structures can be used in industrial and civil buildings as internal and external bearing and enclosing wall structures, and as slabs. According to the LSCS production method, prefabricated panels (walls and slabs) and building site performed constructions are distinguished. The article presents the LSCS subspecies, representing slabs panels made of galvanized profiled steel, density medium grade D400 monolithic foam concrete and sheets "Steklotsem" sheathing, bearing capacity experimental studies results. The paper confirms that such panels can be used in civil buildings and withstand the appropriate load, regulated by the current codes and rules. Moreover, it has been experimentally proved that the foam concrete, despite its own extremely low strength class, actually includes in the operation, preventing such effects as stability local loss, crushing and profile steel elements cross-section warping and increases the slabs overall load capacity by 20 $25 \%$.
\end{abstract}

\section{Introduction}

In the 21st century, much attention is paid to the construction industry development, including building materials and structures.

One of these areas are metal constructions. With the innovative technologies advent and the metallurgy development, they are becoming increasingly popular in the construction process.

The use of lightweight steel thin-walled structures is becoming increasingly popular due to a number of advantages of this structure, namely low metal consumption, availability of manufacturing and transportation, high manufacturability, speed of construction, and consequently, lower costs for the facility construction.

LSTS is widely used abroad, and now they are on the Russian market [1].

\footnotetext{
* Corresponding author: fishermanoff@mail.com
} 
Nowadays, much attention is paid to the energy efficiency issue, as well as to ensuring the fire resistance and fire preservation of structures.

The article [2] shows that the most efficient, from the point of view of energy saving, are buildings built via LSTS frame technology. In [3-5], the behavior of the reinforced concrete slab during fire exposure was considered, and fire resistance calculations were described.

What are the classic structures can be replaced by steel and steel-concrete? The roof system montage via LSTS is an alternative variant of wooden truss structures [6]. In lowstory and modular construction may be applied walls made of steel, sheathed with drywall [7].

But the combination of LSTS with foam concrete is the most popular [8], which may be applied both as enclosing walls [9] and as a floor construction [10]. The work of this technology, the physic-mechanical characteristics, and the behavior of steel elements are described more detailed in [11-14].

The articles [15-19] describe the experience of using foam concrete in the floors and walls construction, and indicate possible methods for strengthening the structure to achieve sufficient strength.

In order for the building structure to be durable, it is necessary to comply with the temperature and moisture conditions [20-22], especially as concerns cellular concrete, which is foam concrete. In the articles [23-24], the consequences of the violation of the specified regime are described on the example of another cellular concrete - aerated concrete.

The effect of temperature loss in the enclosing structures linear elements is presented in article [25]. In [26], the joint work of LSTS and polystyrene concrete as a heater is considered; it is shown that this materials combination is able to minimize heat loss of the building envelope.

The lightweight steel thin-walled structures (LSTS) use in Russia is hampered by the absence of an appropriate regulatory framework. The existing regulatory documents cannot be applied, because they do not take into account the local stability in the early stages of loading loss possibility factor of LSTS [27].

As in any building materials and structures, for example, in concrete with synthetic fiber reinforcement [28], when designing buildings and structures using light steel gauge structures, it is quite important to not forget about its strength characteristics.

In [29], a scheme of tests for "pure" bending, created by applying two concentrated forces equidistant from the supports, was used. This scheme is convenient from the point of view of the stress-strain state; however, it does not reflect the operation of the structures under the actual application of loads on the floor. Numerical studies of the stress-strain state beam structures with external sheet reinforcement are presented in [30].

The steel pipes filled with concrete local stability analysis, as one of the reinforced concrete structures types, is considered in article [31]. For the steel thin-walled structures calculation, the CFSteel program, which operates both in Russian and European standards, can be applied [32].

The opportunities of cold-bent notched c-shaped profile members application are considered in [33]. Initial in-plane rotational stiffness of welded RHS T-joints with axial force in main member are presented in [34].

The work's aim is to identify the nature of the work and insulating non-autoclaved monolithic foam fiber concrete with a $400 \mathrm{~kg} / \mathrm{m} 3$ bulk density, profile steel with fibrous cement cladding, slabs structures samples bearing capacity assessment.

Tasks of the research:

1) The research of slab three identical samples to the bearing capacity loss. 
2) One of the samples, when bringing it to complete destruction, work nature research.

\section{Test methods and main results}

During the research, 5 series of 4 foam concrete cubes samples with various additives were considered.

The identical samples' amount is 3pcs.

The samples' geometrical dimensions are presented in Appendix 1 and correspond to Fig. 1. Overall dimensions are 800x4000 (mm).

The support and the loading are shown in Fig. 2.

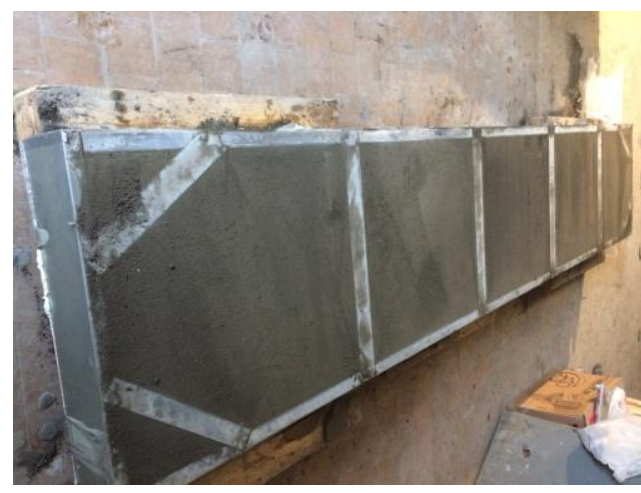

Fig. 1. The samples' general view

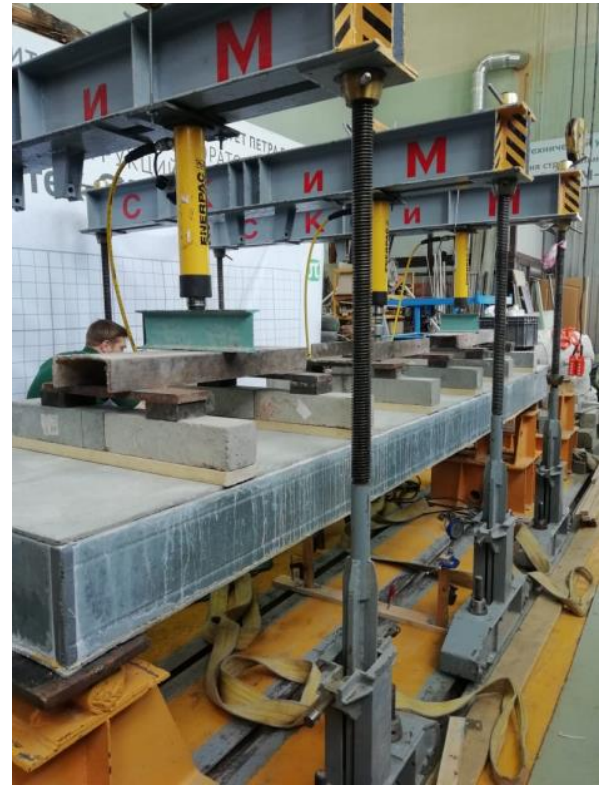

Fig. 2. The samples' support and load.

The support is free, on special hinge supports, as a result of which the tested panels' free span turned out to be $\mathrm{L}=3.85 \mathrm{~m}$

Loading - via 3 jacks, each of which is attached from above to a rigid metal own transverse traverse fixed to the force floor via two racks. From below, jacks rest against an additional metal element or directly into the steel conditionally non-deformable channel shape longitudinal traverse. The longitudinal traverse transmits forces through distribution metal elements to concrete prisms with a section of 150x150 mm and a length of $800 \mathrm{~mm}$, which coincides with the panel's width. These concrete prisms (6 pieces) imitate a concentrated load on the test panel. Between the panel and the concrete prisms, wooden gaskets are laid over the entire contact surface of the prisms and the panel.

Every jack is connected to the same source, in which the external load is specified and its constant value is maintained in all three jacks.

Thus, the accepted loading scheme 6 with concentrated forces can, as is known from the structural mechanics laws, be considered conditionally loaded with a uniformly distributed load, the constancy of which does not depend on the tested samples deformed axis.

To determine the each sample individual points' deflection two deflectometers were installed.

Three samples were investigated. 


\section{1) Sample 1}

The test results are presented in Table 1 and Fig. 3-4.

Table 1. Slab panel's test results (sample 1)

\begin{tabular}{|c|c|c|c|c|r|}
\hline \multirow{2}{*}{ Load, kgf } & \multicolumn{2}{|c|}{$\begin{array}{c}\text { Deflectometers } \\
\text { testimony, } \mathrm{mm} * 10^{-2}\end{array}$} & \multicolumn{2}{|c|}{$\begin{array}{c}\text { Deflections, } \\
\mathrm{mm}\end{array}$} & \multicolumn{2}{c|}{$\begin{array}{c}\text { Slab } \\
\text { deflection, } \\
\text { mm }\end{array}$} \\
\cline { 2 - 5 } & 1 & 2 & 1 & 2 & $\mathbf{0}$ \\
\hline 0 & 7254 & 10393 & 0 & 0 & $\mathbf{1 . 2 4}$ \\
\hline 100 & 7388 & 10507 & 1.34 & 1.14 & $\mathbf{2 . 3 8 5}$ \\
\hline 200 & 7504 & 10620 & 2.5 & 2.27 & $\mathbf{3 . 9 2 5}$ \\
\hline 300 & 7677 & 10755 & 4.23 & 3.62 & $\mathbf{5 . 6 9 5}$ \\
\hline 400 & 7855 & 10931 & 6.01 & 5.38 & $\mathbf{7 . 5 6 5}$ \\
\hline 500 & 8049 & 11111 & 7.95 & 7.18 & $\mathbf{9 . 3 7 5}$ \\
\hline 600 & 8220 & 11302 & 9.66 & 9.09 & $\mathbf{1 1 . 4 9}$ \\
\hline 700 & 8445 & 11500 & 11.91 & 11.07 & $\mathbf{1 3 . 9 5 5}$ \\
\hline 800 & 8670 & 11768 & 14.16 & 13.75 & $\mathbf{1 6 . 8 9}$ \\
\hline 900 & 8972 & 12053 & 17.18 & 16.6 & $\mathbf{1 9 . 5 6 5}$ \\
\hline 1000 & 9220 & 12340 & 19.66 & 19.47 & $\mathbf{2 3 . 1}$ \\
\hline 1100 & 9597 & 12670 & 23.43 & 22.77 & $\mathbf{2 7 . 2 1 5}$ \\
\hline 1200 & 10020 & 13070 & 27.66 & 26.77 & $\mathbf{3 2 . 7 6 5}$ \\
\hline 1300 & 10500 & 13700 & 32.46 & 33.07 & \\
\hline
\end{tabular}

35

30

$\stackrel{\varepsilon}{E}^{25} 20$

5

0

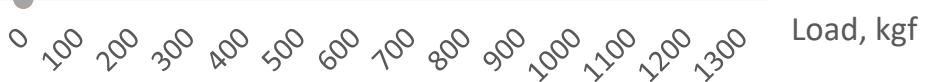

Fig. 3. Samples 1 loading diagram (sensor 1 and sensor 2) 


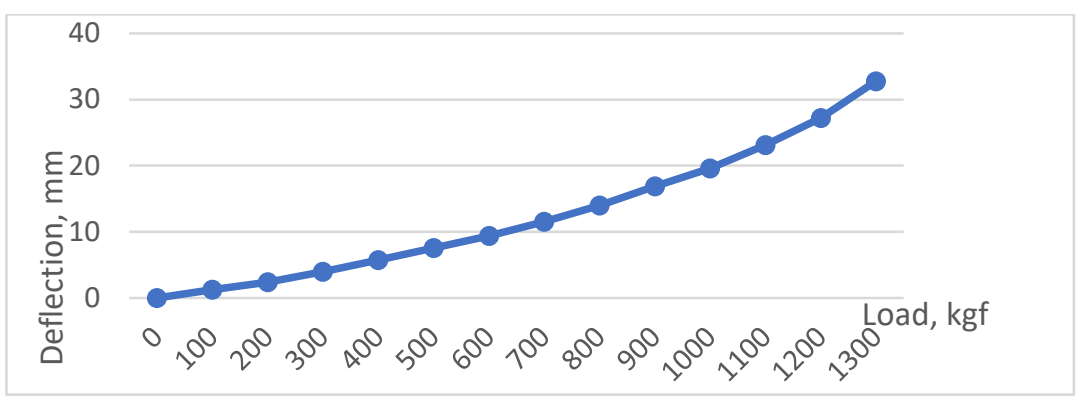

Fig. 4. The deflections curve in the panel's middle (sample 1)

The maximum load was $1.3 \mathrm{tf}$ per 1 jack with a $33 \mathrm{~mm}$ deflection, which corresponds to $422 \mathrm{kgf} / \mathrm{m} 2$. The weight of the transfer equipment and the initial deflection of the panel's own weight were not taken into account.

Further loading was not made, since when trying to maintain a constant effort in the jacks, an increase in displacements occurred, which indicated the exhaustion of the bearing capacity.

\section{2) Sample 2}

The test results are presented in Table 2 and Fig. 5-6:

Table 2. Slab panel's test results (sample 2)

\begin{tabular}{|c|c|c|c|c|r|}
\hline \multirow{2}{*}{ Load, kgf } & \multicolumn{2}{|c|}{$\begin{array}{c}\text { Deflectometers } \\
\text { testimony, mm*10-2 }\end{array}$} & \multicolumn{2}{c|}{$\begin{array}{c}\text { Deflections, } \\
\text { mm }\end{array}$} & $\begin{array}{c}\text { Slab } \\
\text { deflection, } \\
\text { mm }\end{array}$ \\
\cline { 2 - 5 } & 1 & 2 & 1 & 2 & \multicolumn{1}{c|}{$\mathbf{0}$} \\
\hline 0 & 9218 & 12422 & 0 & 0 & $\mathbf{1 . 3 3 5}$ \\
\hline 100 & 9366 & 12303 & 1.48 & 1.19 & $\mathbf{2 . 4 6}$ \\
\hline 200 & 9482 & 12194 & 2.64 & 2.28 & $\mathbf{3 . 9 4}$ \\
\hline 300 & 9635 & 12051 & 4.17 & 3.71 & $\mathbf{6 . 0 8 5}$ \\
\hline 400 & 9899 & 11886 & 6.81 & 5.36 & $\mathbf{7 . 7 8 5}$ \\
\hline 500 & 10075 & 11722 & 8.57 & 7 & $\mathbf{8 . 1 4}$ \\
\hline 600 & 10139 & 11715 & 9.21 & 7.07 & $\mathbf{8 . 9 2}$ \\
\hline 700 & 10295 & 11715 & 10.77 & 7.07 & $\mathbf{9 . 9 6}$ \\
\hline 800 & 10454 & 11666 & 12.36 & 7.56 & $\mathbf{1 1 . 7 4 5}$ \\
\hline 900 & 10625 & 11480 & 14.07 & 9.42 & $\mathbf{1 3 . 5 2}$ \\
\hline 1000 & 10800 & 11300 & 15.82 & 11.22 & $\mathbf{1 5 . 4 9 5}$ \\
\hline 1100 & 11005 & 11110 & 17.87 & 13.12 & $\mathbf{1 7 . 4 7}$ \\
\hline 1200 & 11200 & 10910 & 19.82 & 15.12 & $\mathbf{1 9 . 6 9 5}$ \\
\hline 1300 & 11415 & 10680 & 21.97 & 17.42 & $\mathbf{2 2 . 2 7}$ \\
\hline 1400 & 11680 & 10430 & 24.62 & 19.92 & $\mathbf{2 5 . 1 4}$ \\
\hline 1500 & 11969 & 10145 & 27.51 & 22.77 & $\mathbf{2 8 . 1 7}$ \\
\hline 1600 & 12278 & 9848 & 30.6 & 25.74 & $\mathbf{3 1 . 9 7 5}$ \\
\hline 1700 & 12633 & 9442 & 34.15 & 29.8 & $\mathbf{3 6 . 7 8 5}$ \\
\hline 1800 & 13183 & 9030 & 39.65 & 33.92 & \\
\hline
\end{tabular}




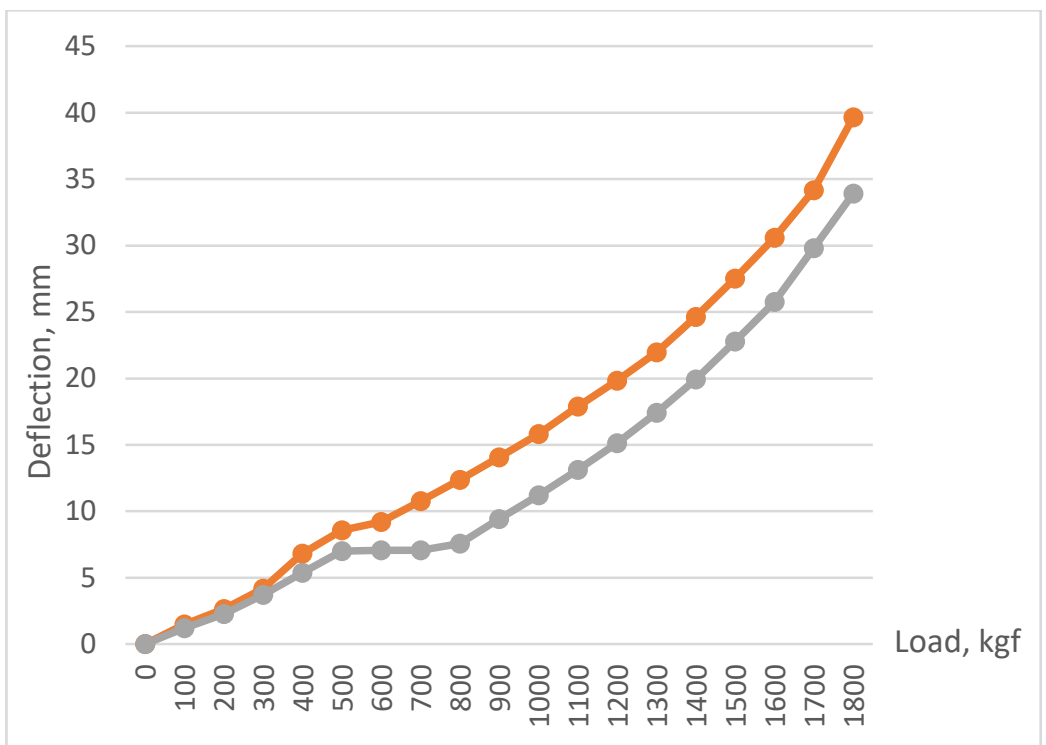

Fig. 5. Sample 2 loading diagram (sensor 1 and sensor 2)

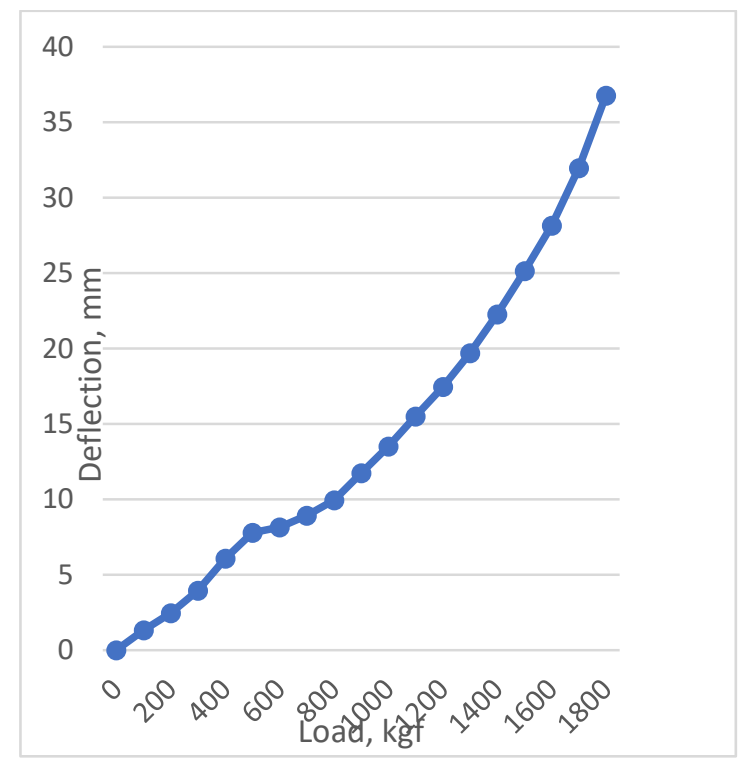

Fig. 6. The deflections curve in the panel's middle (sample 2)

The maximum load was $1.8 \mathrm{tf}$ per 1 jack with a $37 \mathrm{~mm}$ deflection, which corresponds to $584 \mathrm{kgf} / \mathrm{m} 2$. The weight of the transfer equipment and the initial deflection of the panel's own weight were not taken into account.

Further loading was not made, since try to maintain a constant effort in the jacks, an increase in displacements occurred, which indicated the exhaustion of the bearing capacity.

3) Sample 3

The test results are presented in Table 3 and Fig. 7-8: 
Table 3. Slab panel's test results (sample 3)

\begin{tabular}{|c|c|c|c|c|r|}
\hline \multirow{2}{*}{ Load, kgf } & \multicolumn{2}{|c|}{$\begin{array}{c}\text { Deflectometers } \\
\text { testimony, mm*10-2 }\end{array}$} & \multicolumn{2}{c|}{$\begin{array}{c}\text { Deflections, } \\
\mathrm{mm}\end{array}$} & \multirow{2}{*}{$\begin{array}{c}\text { Slab deflection, } \\
\mathrm{mm}\end{array}$} \\
\cline { 2 - 5 } & 1 & 2 & 1 & 2 & $\mathbf{0}$ \\
\hline 0 & 1706 & 11065 & 0 & 0 & $\mathbf{1 . 5 7 5}$ \\
\hline 100 & 1862 & 10906 & 1.56 & 1.59 & $\mathbf{3 . 4 6}$ \\
\hline 200 & 2054 & 10721 & 3.48 & 3.44 & $\mathbf{5 . 4 6 5}$ \\
\hline 300 & 2251 & 10517 & 5.45 & 5.48 & $\mathbf{7 . 4 3 5}$ \\
\hline 400 & 2448 & 10320 & 7.42 & 7.45 & $\mathbf{9 . 7 4 5}$ \\
\hline 500 & 2684 & 10094 & 9.78 & 9.71 & $\mathbf{1 2 . 1 1 5}$ \\
\hline 600 & 2918 & 9854 & 12.12 & 12.11 & $\mathbf{1 4 . 4 4}$ \\
\hline 700 & 3161 & 9632 & 14.55 & 14.33 & $\mathbf{1 7 . 1 9 5}$ \\
\hline 800 & 3410 & 9330 & 17.04 & 17.35 & $\mathbf{2 0 . 2 9 5}$ \\
\hline 900 & 3742 & 9042 & 20.36 & 20.23 & $\mathbf{2 3 . 6 8 5}$ \\
\hline 1000 & 4065 & 8687 & 23.59 & 23.78 & 28.5 \\
\hline 1100 & 4581 & 8240 & 28.75 & 28.25 & 36.52 \\
\hline 1200 & 5369 & 7424 & 36.63 & 36.41 & 40.145 \\
\hline 1300 & 5733 & 7063 & 40.27 & 40.02 & \\
\hline
\end{tabular}

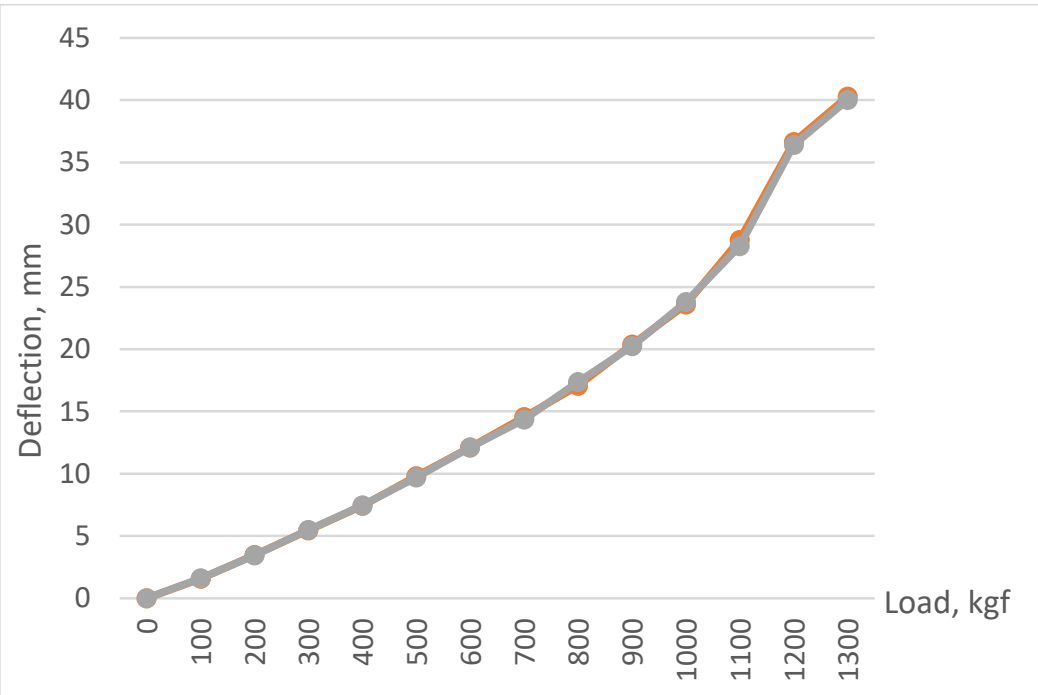

Fig. 7. Sample 3 loading diagram (sensor 1 and sensor 2)

The maximum load was 1.1 tf per 1 jack with a $40 \mathrm{~mm}$ deflection, which corresponds to $357 \mathrm{kgf} / \mathrm{m} 2$. The weight of the transfer equipment and the initial deflection of the panel's own weight were not taken into account. 


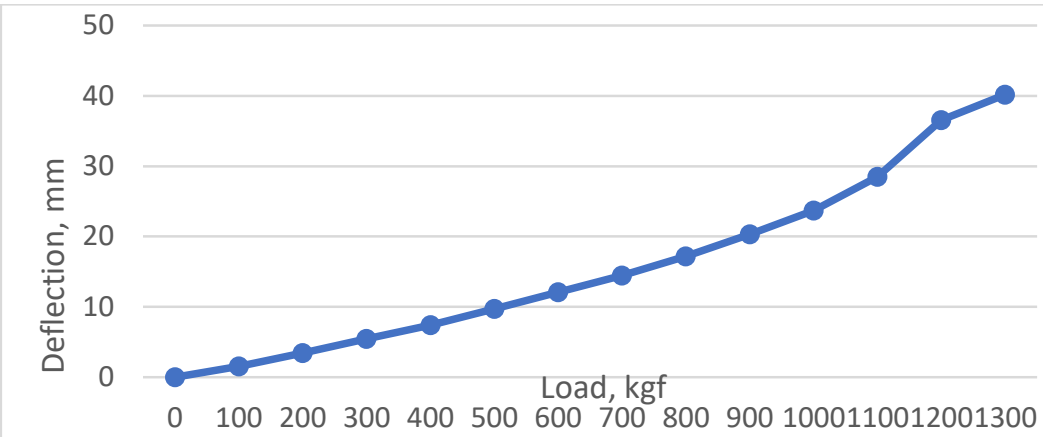

Fig. 8. The deflections curve in the panel's middle (sample 3)

\section{The results' reliability}

Sample 3 was subjected to a complete destruction by efforts maintaining in the jacks, accompanied by an increase in displacements and, at the same time, a decrease in the magnitude of the efforts in the jacks. In the destruction course, the various sizes cracks presence in foam concrete, facing panels "Steklotsem" local cracking is noted. The final loss of bearing capacity is caused by the profile steel destruction (Fig. 9) - the achievement of the tensile strength in the stretched fibers and the local loss of stability in the upper edges of the compressed zone.

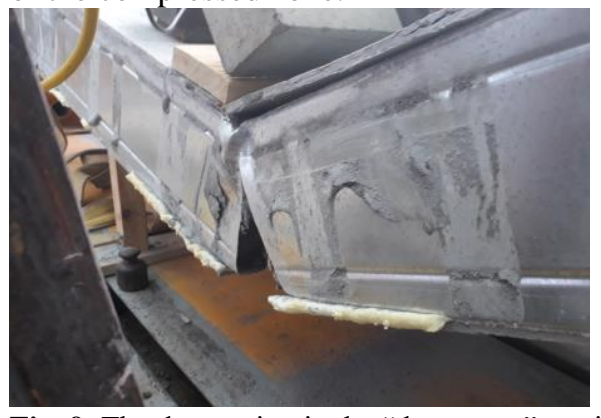

Fig. 9. The destruction in the "dangerous" section

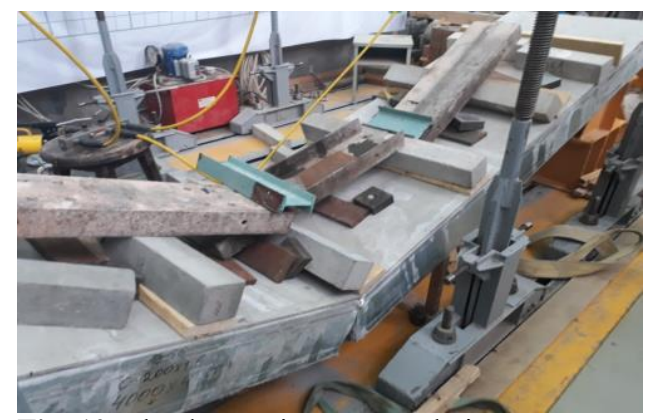

Fig. 10. The destruction's general view

The dangerous section location is the left bar under the central jack (the third (out of five) in a row from left to right "concentrated" force) - Fig.10:

This circumstance is due to the fact that the maximum bending moment ("pure" bending) occurs within the space between the bars of the central jack with a transverse force equal to zero. In addition, the two most "dangerous" sections are the sections under the central jack bars, in which a transverse force already occurs, equal to a half the force in the jack. In one of these sections the destruction appeared.

\section{Conclusion}

1. The research has shown that the maximum load on the slab varies from $1.1 \mathrm{tf}$ to $1.8 \mathrm{tf}$ per jack, which corresponds to the slabs' bearing capacity $357 \ldots .484 \mathrm{kgf} / \mathrm{m}^{2}$

2. The ultimate load value corresponds to a certain range of deflection values $-33 \ldots 40$ $\mathrm{mm}$, which indicates a possible difference in the stiffness samples' values (most likely due to different characteristics of foam concrete - humidity, density, etc.), which indirectly indicates the capture of foam concrete on the part of the stress.

3. The panels' final destruction occurs on the profile steel. 
4. In general, the experiment showed that foam concrete, despite its low strength properties, has a positive effect on the operation of the panels (participation in the redistribution of stresses, partial or complete prevention of local stress effects in the profile steel, such as stability local loss, warping, crushing etc.). In this connection, it is recommended to develop a method for slab panels calculating, in which it is necessary to quantitatively take into account the effect of foam concrete on panels' stress-strain state, for which additional research is advisable.

\section{References}

1. D.O. Sovetnikov, N.V. Videnkov, D.A. Trubina, Constr. Un. Build. Struct., 3(30), 152$165(2015)$

2. A.V. Orlova, E.N. Zhmarin, K.O. Paramonov, Constr. Un. Build. Struct., 6(11), 1-13 (2013)

3. V.A. Rybakov, I.A. Ananeva, A.O. Rodicheva, O.T. Ogidan, Mag. Civ. Eng., 6(74), 161-174 (2017)

4. A.V. Bushmanova, D.K. Kharchenko, K.S. Semenov, Yu.G. Barabanshchikov, V.K. Korovina, A.V. Dernakova, Mag. Civ. Eng., 3(79), 45-53 (2018)

5. E. Nedviga, N. Beresneva, M. Gravit, A. Blagodatskaya, Adv. Int. Syst. Comp., 692, 739-749 (2018)

6. V.A. Rybakov, M. Al Ali, A.P. Panteleev, K.A. Fedotova, A.V. Smirnov, Mag. Civ. Eng., 8(76), 28-39 (2017)

7. A.D. Ariyanayagam, M. Mahendran, Thin-Wall. Struct., 130, 487-504 (2018)

8. M.K. Bronzova, N.I. Vatin, M.R. Garifullin, Constr. Un. Build. Struct., 1(28), 74-90 (2015)

9. Y. Geng, Y. Wang, J. Ding, W. Xu, J. Build. Struct., 37, 141-150 (2016)

10. R.H.M. Rum, Z.M. Jaini, N.H. Abd Ghaffar, N. Abd Rahma, Materials Science and Engineering, 271(1), 012102(2017)

11. J.H. Ye, W. Chen, Int. J. Struct. Stab. Dyn., 13(1), 1-29 (2013)

12. P. Prabha, G.S. Palani, N. Lakshmanan, R. Senthil, KSCE J. Civ. Eng., 22(9), 35343545 (2018)

13. M. Jerman, M. Keppert, J. Výborný, R. Černý, Const. Build. Mat., 41, 352-359 (2013)

14. A. Ahmadi, C. Mathieson, G. Clifton, R. Das, J. Lim, J. Const. Steel Res., 122, 70-79 (2016)

15. J. Hulimka, R. Krzywoń, A. Jędrzejewska, Proc. Eng., 193, 337-344 (2017)

16. M. Kozłowski, M. Kadela, Proc. Eng., 161, 468-476 (2016)

17. J. Vlcek, M. Drusa, W. Scherfel, B. Sedlar, Earth and Environmental Science, 95, 022049 (2017)

18. R.B. Orlovich, V.V. Bespalov, V.N. Derkach, Mag. Civ. Eng., 3(79), 112-119 (2018)

19. V.V. Bespalov, D. Ucer, , I. D. Salmanov, I.N. Kurbanov, S.V. Kupavykh, Mag. Civ. Eng., 2(78), 136-150 (2018)

20. D.S. Tarasova, M.R Petritchenko, Mag. Civ. Eng., 4(72), 28-35 (2017)

21. E.A. Statcenko, A.F. Ostrovaia, T.A. Musorina, M.I. Kukolev, M.R. Petritchenko, Mag. Civ. Eng., 8(68), 86-91 (2016) 
22. A.B. Krutilin, Y.A. Rykhlionak, V.V. Liashkevich, Mag. Civ. Eng., 2(54), 46-55 (2015)

23. N.I. Vatin, A.S. Gorshkov, S.V. Kornienko, I.I. Pestryakov, Constr. Un. Build. Struct., 1(40), 78-101 (2016)

24. D.A. Alyabyeva, Constr. Un. Build. Struct., 8(35), 24-35 (2015)

25. O.D. Samarin, Mag. Civ. Eng., 2(70), 3-10 (2017)

26. M.V. Leshchenko, V. Semko, Mag. Civ. Eng., 8(60), 44-55 (2015)

27. D.A. Trubina, L.A. Kononova, A.A. Kaurov, E.D. Pichugin, D.A. Abdulaev, Constr. Un. Build. Struct., 4(19), 109-127 (2014)

28. A.I. Kirsanov, O.N. Stolyarov, Mag. Civ. Eng., 4(80), 15-23 (2018)

29. V.I. Travush, D.V. Konin, A.S. Krylov, Mag. Civ. Eng., 1(77), 90-100 (2018)

30. V.N. Medvedev, S.D. Semenyuk, Mag. Civ. Eng., 3(63), 3-15 (2016)

31. R.A. Kanishchev, Mag. Civ. Eng., 4(64), 59-68 (2016)

32. A.A. Kikot, Mag. Civ. Eng., 1(61), 42-59 (2016)

33. N. Vatin, T. Nazmeeva, R. Guslinscky, Adv. Mate. Res., 941-944, 1871-1875 (2014)

34. M. Garifullin, S. Pajunen, K. Mela, M. Heinisuo, J. Havula, J. Constr. Steel Res., 139, 353-362 (2017) 